Transport and Communications Science Journal, Vol. 72, Issue 7 (09/2021), 800-810

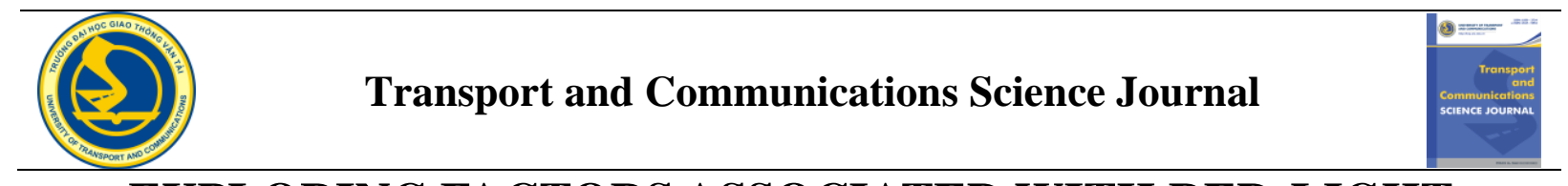

\title{
EXPLORING FACTORS ASSOCIATED WITH RED-LIGHT RUNNING: A CASE STUDY OF HANOI CITY
}

\author{
Chu Tien Dung* \\ Department of Highway and Traffic Engineering, Faculty of Civil Engineering, University of \\ Transport and Communications, No 3 Cau Giay Street, Lang Thuong Ward, Dong Da District, \\ Hanoi, Vietnam
}

\author{
ARTICLE INFO \\ TYPE: Research Article \\ Received: 04/06/2021 \\ Revised: $25 / 08 / 2021$ \\ Accepted: 05/09/2021 \\ Published online: 15/09/2021 \\ https://doi.org/10.47869/tcsj.72.7.3 \\ * Corresponding author \\ Email: dungchu@utc.edu.vn
}

\begin{abstract}
Red-light running (RLR) is the most significant factor involved in traffic crashes and injuries at signalized intersections. In Vietnam, little knowledge of factors affecting RLR has been found. This paper applied an ordered probit model to investigate factors associated with RLR using questionnaire data collected in Hanoi. Generally, this paper found that males and motorcyclists have a higher likelihood of RLR than females and car drivers. In addition, the younger and lower-income road users and the ones who are businessmen and who have a commuting trip in off-peak hours are more likely to run the red light. By contrast, the road users who go to school and the people who understand traffic law are less likely to violate the red light. In the future, it is necessary to collect data in different cities to generalize the results. In addition, may need to apply a more powerful method such as the latent class model, which can discover hidden facts among respondents. In the new model, other factors such as weather, waiting time, and countdown signal will be considered to investigate their effects on RLR.
\end{abstract}

Keywords: red-light running, signalized intersections, ordered probit model, motorcycle, traffic crash. 


\section{INTRODUCTION}

The intersections are the most complicated traffic facilities in the road networks, and traffic crashes are likely to occur at this location, which is accounted for approximately $50 \%$ [1]. Therefore, traffic lights are installed at busy intersections to reduce critical conflicts and traffic crashes. However, the level of safety achieved strongly depends on the signal's compliance of road users. The road users who disobey the traffic law and commit red-light running (RLR) may put themselves and the other road users at severe crashes. RLR is a dangerous behavior since crashes involved RLR usually result in severe injuries and fatalities $[2,3]$.

Retting et al. [4] found that 3\% of all fatal crashes between 1992 and 1996 involved redlight running (RLR). Fatalities related to RLR increased by approximately $15 \%$ during this period (from 702 in 1992 to 809 in 1996). In addition, it is not surprising that the urban areas are at greater risk for RLR crashes [5]. Brittany et al. [6] estimated that $20 \%$ of vehicles involved in fatal crashes at signalized intersections disobeyed the traffic lights. In 2018, 846 people were killed, and an estimated 139,000 were injured in crashes that involved red-light running. About half of the deaths in these crashes were pedestrians and occupants in other vehicles who were hit by the red-light runners [7]. In developing countries, according to WHO [8], there has been no reduction in the number of road traffic deaths in any low-income country since 2013 and the risk is more than three times higher in low-income countries than in high-income countries. Thus, more studies and actions about traffic safety are needed in these countries.

In Vietnam, the traffic is mixed, and motorcycles (MCs) are dominant. The MCs belong to a vulnerable group, and they are associated with a high rate of fatalities [8]. The general statistics office of Viet Nam [9] reported that 5,508 traffic accidents occurred nationwide during the first five months of 2020. The accident caused 2,667 deaths. On average, 36 traffic accidents occurred nationwide each day during this period, causing 17 deaths per day. Therefore, taking action to reduce traffic accidents in general and to control RLR specifically is very important. The objective of this paper is to examine the factors associated with RLR by using an ordered probit model (OPM).

\section{LITERATURE REVIEW}

Several studies have been conducted to investigate the factors that affect the RLR. Jensupakarn and Kanitpong [3] examine various factors for RLR in Thailand and found that not only road user characteristics (i.e., age, gender, occupation) but also the road environments (i.e., the number of lanes, type of traffic light pole, length of yellow time, and approaching speed) significantly affect RLR behavior. A study of Al-Atawi [10] showed that engineering characteristics, e.g., lane width, speed, traffic volume, and red time interval significantly influence the RLR rate. Wang et al. [11] concluded that males have a higher likelihood to commit RLR than females and the large traffic volume increases the potential of RLR. Similar to Wang et al. [11], Chen et al. [12] also found that males are likely to run the red light than females. In addition, the factors including young motorcyclists, types of MCs, approaching speeds, and helmets used, significantly affect RLR. Day and time are the other factors that are significantly associated with RLR. Yan et al. [2] found that on holidays, the RLR rate was 1.89 times higher than that on weekdays. The motorcyclists are likely to run the red light in off-peak hours, but they are less likely to violate on weekends and holidays. This 
conclusion is different from the study of Yang and Najm [13], which showed that off-peak hours resulted in lower violation counts. Porter and Berry [14] found that younger respondents were more likely to be violators. Chen et al. [15] investigated RLR and concluded that RLR most possibly occurred on weekdays during peak hours under the higher traffic volumes and longer cycle time. Bonneson and Zimmerman [16] investigated the effect of yellow time on the RLR frequency and concluded that increasing yellow time could lead to a decrease in RLR frequency up to 50\%. Similarly, Retting et al. [17] also suggested that providing longer yellow times could reduce RLR by $36 \%$. Long et al. [18] examined the effect of countdown signals on RLR and they concluded that the existence of these devices remarkably increases the RLR rate. The weather is another factor that affect RLR such as hot weather $[19,20]$ and the rain $[20]$.

In Vietnam, comprehensive studies regarding RLR are quite limited. Mai et al. [21] conducted a study based on observational data using a camera at two signalized intersections in Hanoi. Their analysis showed that cars have less RLR rate $(2 \%)$ than MCs $(25 \%)$. Additionally, the early departure (road users stop at the red light but go in the intersection 5 seconds before the green light) accounted for a large proportion (car: $57.69 \%$ and MCs: $58.84 \%$ ). Vuong et al. [19] collected data at one signalized intersection to investigate RLR behavior. Total 1302 cases of RLRs were recorded during the observation period. Among them, motorcycle and bicycle account for a large proportion of RLR violations, approximately 98.8\%. Tran et al. [22] used a logistic model to study factors associated with crash injury severity at signalized intersections in Ho Chi Minh. The results show that the involvement of motorcycles, intersection location (e.g., located in central, newly developed, and developing areas), road type, illegal overtaking, and approach width might be contributing factors to the accident severity.

\section{METHODOLOGY}

To examine the effects of factors on RLR, there are several approaches. The t-test and ANOVA (analysis of variance) which examine whether group means differ from one another can be applied. The t-test compares two groups, while ANOVA can do more than two groups. In addition, if analysts wish to examine the association between a continuous outcome and a continuous variable they use a linear regression, which associates the two variables through a $\beta$ coefficient. This can easily be generalized to multiple regression, where we consider several covariates at the same time to try to understand their joint relationship to the outcome.

The t-test can be thought of as a simple regression model with the covariate taking on only two values, and the ANOVA can also be viewed as a regression model with multiple covariates. More complicated ANOVA models can also be thought of in regression frameworks. Regression analysis is a mathematical method that determines which independent variables have the most effect on a dependent variable. It helps to determine which factors can be ignored and those that should be emphasized. The regression approach requires more work, but it allows us to consider all these models in one unified framework and thus allows complete control of the comparisons made. Further, the calculation of the $\beta$ coefficients and standard errors for these coefficients allows us to use confidence intervals rather than relying on hypothesis tests as in the ANOVA.

These three procedures are the main ways of dealing with the association of a continuous variable with continuous or categorical (grouping) covariates. The regression approach has 
many advantages, including the unified framework, the easy use of confidence intervals, and the option to manipulate the covariates, which usually make it the best choice. In addition, the other advantage of regression model is making predictions and forecasts future results. Therefore, this paper applied the regression approach instead of the t-test or ANOVA.

According to [23], the ordered choice model is common for analysts to seek out the opinions of individuals and organizations using attitudinal scales such as degree of satisfaction or importance attached to an issue. Examples include rating systems (poor, fair, good excellent), opinion surveys from strongly disagree to strongly agree, grades, bond ratings, and usage frequency of public transport. Ordered choice models provide a relevant methodology for capturing the sources of influence that explain the choice made among a set of ordered alternatives. In this research, RLR frequency (1: never, 2: seldom, 3: sometimes, and 4: frequently) is ordered categories. It is used as an independent variable; therefore, the ordered choice model is applied for this study. It is noteworthy, the ordered choice model can be probit or logit. However, logit and probit models are basically the same, the difference is in the distribution. The ordered logit model uses cumulative standard logistic distribution (F) while the ordered probit model applies cumulative standard normal distribution $(\Phi)$. Both models provide similar results [24].

The ordered probit model is explained as follows [23]. Let's denote $y_{i}^{*}$ as the utility functions of RLR frequency as shown in Eq. (1).

$$
\mathrm{y}_{\mathrm{i}}^{*}=\gamma+\beta \mathrm{x}_{\mathrm{i}}+\varepsilon_{\mathrm{i}}
$$

Where $y_{i}^{*}$ is the exact but unobserved dependent variable, $x_{i}$ is a vector of explanatory variable of individual $i, \gamma$ is a constant term and $\beta$ is a vector of the unknown parameter to be estimated. $\varepsilon_{\mathrm{i}}$ is a random error term assuming to follow a normal distribution with zero mean.

Further suppose that while we cannot observe $y_{i}^{*}$, we instead can only observe the categories of response:

$$
\mathrm{y}_{\mathrm{i}}=\mathrm{j} \quad \text { if } \mu_{\mathrm{j}-1}<\mathrm{y}_{\mathrm{i}}^{*} \leq \mu_{\mathrm{j}} \quad \mathrm{j}=1,2, \ldots \ldots, \mathrm{J}
$$

$\mu$ is a threshold parameter to be estimated and $y_{i}$ is the observed values of RLR frequency. The RLR frequency was observed as categories $\mathrm{y}_{\mathrm{i}}$ a choice set $j=\{1,2,3,4\}$ for intervals of "never", "seldom", "sometimes", and "frequently". Then, the probability that individual $i$ will select alternative $\mathrm{j}$ is:

$$
\mathrm{P}\left(\mathrm{y}_{\mathrm{i}}=\mathrm{j} \mid \mathrm{x}_{\mathrm{i}}\right)=\Phi\left\{\mu_{\mathrm{j}}-\left(\gamma+\beta \mathrm{x}_{\mathrm{i}}\right)\right\}-\Phi\left\{\mu_{\mathrm{j}-1}-\left(\gamma+\beta \mathrm{x}_{\mathrm{i}}\right)\right\}
$$

Normally, if $\mu_{0}=-\infty$ and $\mu_{\mathrm{J}}=\infty$ then $\Phi(-\infty)=0$ and $\Phi(\infty)=1$. However, these probabilities consist of too many parameters, and we cannot identify all threshold parameters if the constant is included in the model. Therefore, we need to normalize one parameter, either to eliminate the constant term $(\gamma)$ or to fix the first threshold parameter $\left(\mu_{1}\right)$ to zero [23]. In the current paper, the first threshold parameter is set to zero. Finally, the likelihood function for the entire observations can be drawn as:

$$
\mathrm{L}\left(\beta, \mu_{\mathrm{j}}, \mu_{\mathrm{j}-1}, \mathrm{x}_{\mathrm{i}}\right)=\prod_{\mathrm{i}=1}^{\mathrm{I}} \prod_{\mathrm{j}=1}^{\mathrm{J}}\left[\mathrm{P}_{\mathrm{r}}\left(\mathrm{y}_{\mathrm{i}}=\mathrm{j} \mid \mathrm{x}_{\mathrm{i}}\right)^{\mathrm{h}_{\mathrm{ij}}}\right]
$$

Where, $\mathrm{h}_{\mathrm{ij}}$ equals 1 if the respondent $i$ chooses outcome $j$, otherwise $\mathrm{h}_{\mathrm{ij}}$ equals 0 . Our 803 
paper used the maximum log likelihood estimation method implemented in $\mathrm{R}$ programming language to estimate the unknown parameters.

\section{DATA}

Our paper used the dataset conducted by questionnaire survey in January 2020. The questionnaire was distributed and collected by an online survey and in-person survey within two weeks (from 6th - 19th). The online survey was conducted by posting questionnaires through social media (e.g., Facebook). And the in-person survey was conducted by interviewing respondents at their homes, at coffee shops, and while waiting to pick up their kids at school. Finally, 883 respondents agreed to answer the questionnaire. However, among 504 respondents collected online, it is needed to exclude 87 respondents because they ignored questions in the questionnaire sheets. In addition, of 796 valid samples, 45 bus users were excluded since they are not subjected to this study. Therefore, the data remain 751 respondents who used private cars, motorcycles, electric bicycles, and bicycles as their transportation modes for commuting. Table 1 summarizes the information got from questionnaires.

Table 1. Summary of information got from questionnaires.

\begin{tabular}{ll}
\hline \multicolumn{1}{c}{ Questionnaire group } & \multicolumn{1}{c}{ Information asked } \\
\hline $\begin{array}{l}\text { Demographic characteristics } \\
\text { Mobility characteristics }\end{array}$ & $\begin{array}{l}\text { Age } \text {, gender, academic level, occupation, monthly income } \\
\text { Driver license, commuting mode/frequency/time/purpose, } \\
\text { children accompaied, distance/time to work place }\end{array}$ \\
$\begin{array}{l}\text { Knowledge of traffic law } \\
\text { Opinions and awareness of road } \\
\text { users }\end{array}$ & $\begin{array}{l}\text { How to stop at traffic light?, what is RLR, amercement for RLR } \\
\text { Dangerous level of yellow/RLR, safety level, consciousness of } \\
\text { road users, congestion level, pollution level, feeling to wait } \\
\text { under hot/rainy/cold weather, waiting time } \\
\text { Questions related to RLR } \\
\text { Have you ever violated the red light? Factors affect your RLR } \\
\text { (hot/rainy/cold weather, air pollution, pressure of being late, } \\
\text { behavior of surounding people, police, waiting time) } \\
\text { Strengthen the penalty, enforcement cameras, publicize the } \\
\text { violators, driving license point deduction, educate awareness of } \\
\text { citizen }\end{array}$ \\
$\begin{array}{l}\text { What government should do to } \\
\text { reduce RLR }\end{array}$ \\
$\begin{array}{l}\text { *) The respondent born after 2002 (under 18 years old) was not subjected for questionnaire. The oldest } \\
\text { one in the data set was born in 1945 (75 years old). }\end{array}$
\end{tabular}

Table 2 summarizes some characteristics of respondents. From this table, we can observe that males have a higher proportion (61\%) than females $(39 \%)$. Almost all respondents are younger than 35 years old (i.e., age $18-25: 36 \%$ and age $25-35: 32 \%$ ). The respondents whose occupation is government employee, private employee, and student account for $25 \%$, $29 \%$, and $23 \%$, respectively. Regarding the transportation modes, a considerable proportion of respondents use MCs (87\%), whereas car users account for only 10\%. Most of the respondents are going to work $(70 \%)$ or to school $(23 \%)$.

Figure 1 represents the RLR frequency. It is found that, among 751 cases, only 137 respondents, accounting for $18 \%$, reported never committed RLR. The other 82 percent of respondents have violated the red light at least once. The RLR frequency was used in the ordered probit model as an independent variable. 
Transport and Communications Science Journal, Vol. 72, Issue 7 (09/2021), 800-810

Table 2. Respondents' characteristics.

\begin{tabular}{|c|c|c|}
\hline \multicolumn{2}{|c|}{ Item } & \multirow{2}{*}{ Proportion } \\
\hline Gender & Male & \\
\hline & Female & $39 \%$ \\
\hline \multirow{4}{*}{ Age } & Under 25 & $36 \%$ \\
\hline & 25 to 35 & $32 \%$ \\
\hline & 35 to 45 & $23 \%$ \\
\hline & Over 45 & $9 \%$ \\
\hline \multirow{6}{*}{ Occupation } & Government employee & $25 \%$ \\
\hline & Private employee & $29 \%$ \\
\hline & Student & $23 \%$ \\
\hline & Business & $11 \%$ \\
\hline & Freelance work & $8 \%$ \\
\hline & Retired & $4 \%$ \\
\hline \multirow{5}{*}{ Income/month $\left(10^{6}\right)$} & Under 5 & $29 \%$ \\
\hline & 5 to 7 & $17 \%$ \\
\hline & 7 to 10 & $28 \%$ \\
\hline & 10 to 20 & $20 \%$ \\
\hline & Over 20 & $6 \%$ \\
\hline \multirow{4}{*}{ Transportation mode } & Car & $10 \%$ \\
\hline & Motorcycle & $87 \%$ \\
\hline & Electric bicycle & $2 \%$ \\
\hline & Bicycle & $1 \%$ \\
\hline \multirow{4}{*}{ Trip purpose } & Work & $70 \%$ \\
\hline & School & $23 \%$ \\
\hline & Shopping & $1 \%$ \\
\hline & Other & $6 \%$ \\
\hline
\end{tabular}

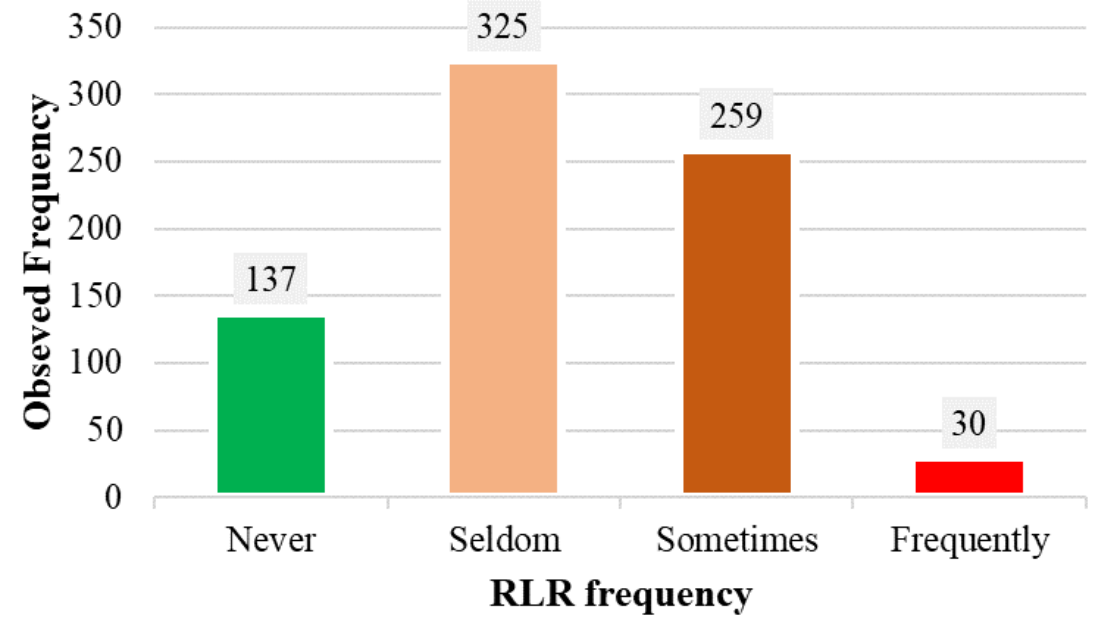

Figure 1. Distribution of red-light running frequency. 


\section{RUSULTS AND DISCUSSION}

Table 3 present the estimation results of the ordered probit model. It is worth mentioning that before estimating the parameters, correlations were calculated to determine the relationship among variables. In this paper, Pearson correlation $(r)$ is used to measure the strength and direction of a linear relationship between two variables. Mathematically this can be done by dividing the covariance of the two variables by the product of their standard deviations (see Eq. (5)).

$$
\mathrm{r}=\mathrm{r}_{\mathrm{xy}}=\frac{\operatorname{cov}(\mathrm{x}, \mathrm{y})}{\mathrm{S}_{\mathrm{x}} \mathrm{S}_{\mathrm{y}}}
$$

The value of correlation ranges between -1 and 1 . A correlation of -1 shows a perfect negative correlation, while a correlation of 1 shows a perfect positive correlation. A correlation of 0 shows no relationship between the movement of the two variables. The correlation matrix is shown in Table 4. The table indicates that the correlation among variables is low (value $<0.3$ ). Therefore, all variables can be used in the model.

Regarding goodness of fit, this paper used rho-squared $\left(\rho_{0}^{2}\right)$ and adjusted rho-squared $\left(\bar{\rho}_{0}^{2}\right)$ as shown in Eq. (6) and Eq. (7), respectively. In addition, adjusted rho-squared $\left(\bar{\rho}_{0}^{2}\right)$ is used to penalizes the addition of parameters. Rho-square $\left(\rho_{0}^{2}\right)$ can be interpreted like R-squared in linear regression model. Its value ranges between 0 and 1 and the bigger value shows the better fit. However, it can not be as big as R-squared. According to McFadden [25], the values from 0.2 - 0.4 indicate a good model fit. Therefore, as indicated in Table 3, the goodness of fit is acceptable in this paper.

$$
\begin{gathered}
\rho_{0}^{2}=\frac{L L_{\beta}}{L L_{0}} \\
\bar{\rho}_{0}^{2}=\frac{L L_{\beta}-p}{L L_{0}}
\end{gathered}
$$

Where, $L L_{\beta}$ is log likelihood full model, $L L_{0}$ is $\log$ likelihood empty model, and $p$ is the number of parameters.

From Table 3, it is found that males are more possibly to commit RLR than females. This result is consistent with findings in previous studies [3, 11, 12]. A reason associated with this fact is that males are more aggressive but less patient than females. In addition, they are risktaking road users. Therefore, males more frequently run a red light than females. Age is another significant factor that affects $\operatorname{RLR}[3,12,14]$. These studies concluded that younger drivers are more likely to run a red light. As seen in Table 3, our result compares well with this finding that respondents less than 50 years old have a higher RLR frequency than the older ones.

Besides gender and age, occupation is significantly affected the RLR frequency. That is, the businessman is more likely to commit RLR than other occupations. Our finding comparable to those of Jensupakarn and Kanitpong [3]. In addition, transportation modes are also a significant factor contributing to RLR. The road users who use cars for commuting are less likely to commit RLR than the other two-wheeler riders (motorcyclists, bicyclists). This finding is consistent with observational studies $[2,21]$ ), in which their result showed that cars have a lower RLR rate than motorcycles. It is because cars are less flexible, and they are penalized more strictly for RLR than motorcycles. 
Transport and Communications Science Journal, Vol. 72, Issue 7 (09/2021), 800-810

Table 3. Estimation results of ordered probit model.

\begin{tabular}{|c|c|c|c|c|c|c|}
\hline Variables & Note & Parameter & Std_err ? & T_value & P_value & Sig. \\
\hline Constant & & 1.124 & 0.153 & 7.35 & 0.0000 & $* * *$ \\
\hline Male $($ dummy, male $=1$, female $=0$ ) & Var 1 & 0.262 & 0.084 & 3.12 & 0.0009 & $* * *$ \\
\hline Age (dummy, $1=$ less than $50,0=$ otherwise $)$ & Var 2 & 0.531 & 0.208 & 2.55 & 0.0054 & $* *$ \\
\hline Occupation is business (dummy) & Var 3 & 0.413 & 0.168 & 2.46 & 0.0069 & $* *$ \\
\hline Individual monthly income ${ }^{1)}$ & Var 4 & -0.075 & 0.041 & -1.83 & 0.0336 & $*$ \\
\hline Using cars for commuting (dummy) & Var 5 & -0.496 & 0.146 & -3.4 & 0.0003 & $* * *$ \\
\hline Commuting during peak-hours (dummy) & Var 6 & -0.206 & 0.099 & -2.08 & 0.0188 & $* *$ \\
\hline Trip purpose is going to school (dummy) & Var 7 & -0.324 & 0.119 & -2.72 & 0.0033 & $* * *$ \\
\hline Understand amercement for RLR (dummy) & Var 8 & -0.227 & 0.081 & -2.8 & 0.0026 & $* * *$ \\
\hline Know how to stop at traffic light (dummy) & Var 9 & -0.203 & 0.086 & -2.36 & 0.0091 & $* *$ \\
\hline \multicolumn{7}{|l|}{ Threshold parameters } \\
\hline$\mu 1$ (Normalized to zero) & & 0 & & & & \\
\hline$\mu 2$ & & 1.12 & 0.026 & 43.08 & 0.0000 & $* * *$ \\
\hline$\mu 3$ & & 1.234 & 0.036 & 34.28 & 0.0000 & $* * *$ \\
\hline \multicolumn{7}{|l|}{ Goodness of fit } \\
\hline Number of parameters $(p)$ & & 12 & & & & \\
\hline Sample's size $(\mathrm{N})$ & & 751 & & & & \\
\hline Log likelihood empty model $\left(L L_{0}\right)$ & & -1164.66 & & & & \\
\hline Log likelihood full model $\left(L L_{\beta}\right)$ & & -848.513 & & & & \\
\hline Rho-squared $\rho_{0}^{2}$ & & 0.271 & & & & \\
\hline Adjusted rho-squared $\bar{\rho}_{0}^{2}$ & & 0.261 & & & & \\
\hline Note & & & & & & \\
\hline
\end{tabular}

Table 4. Correlation among variables.

\begin{tabular}{lccccccccc}
\hline Variable & Var 1 & Var 2 & Var 3 & Var 4 & Var 5 & Var 6 & Var 7 & Var 8 & Var 9 \\
\hline Var 1 & $\mathbf{1 . 0 0}$ & 0.06 & 0.02 & -0.03 & 0.10 & 0.02 & 0.13 & 0.02 & -0.06 \\
Var 2 & 0.06 & $\mathbf{1 . 0 0}$ & -0.05 & -0.03 & 0.02 & 0.04 & -0.11 & 0.04 & -0.05 \\
Var 3 & 0.02 & -0.05 & $\mathbf{1 . 0 0}$ & 0.15 & -0.01 & -0.01 & -0.14 & -0.02 & 0.05 \\
Var 4 & -0.03 & -0.03 & 0.15 & $\mathbf{1 . 0 0}$ & 0.29 & -0.02 & -0.28 & 0.02 & -0.09 \\
Var 5 & 0.10 & 0.02 & -0.01 & 0.29 & $\mathbf{1 . 0 0}$ & -0.06 & -0.16 & 0.08 & -0.05 \\
Var 6 & 0.02 & 0.04 & -0.01 & -0.02 & -0.06 & $\mathbf{1 . 0 0}$ & 0.03 & -0.03 & 0.10 \\
Var 7 & 0.13 & -0.11 & -0.14 & -0.28 & -0.16 & 0.03 & $\mathbf{1 . 0 0}$ & 0.02 & 0.06 \\
Var 8 & 0.02 & 0.04 & -0.02 & 0.02 & 0.08 & -0.03 & 0.02 & $\mathbf{1 . 0 0}$ & -0.12 \\
Var 9 & -0.06 & -0.05 & 0.05 & -0.09 & -0.05 & 0.10 & 0.06 & -0.12 & $\mathbf{1 . 0 0}$ \\
\hline
\end{tabular}

A few studies [3, 15] found that time of day significantly influences RLR. RLR most possibly happed on weekdays during peak-hours when traffic volumes are high [15]. Our result is in contradiction to those studies since we found that the road users who usually have commuting trips in peak hours have less frequency of RLR. By contrast, they have a higher likelihood of running the red light in off-peak hours with relatively low traffic volume. This finding is in good agreement with the study conducted by Yan et al. [2], in which the RLR 
rate was higher in off-peak periods. It implies that those violators in off-peak hours are aggressive and risk-taking. This characteristic motivates them to run red-light. Such violators may put themself and other road users into serious crashes since the speeds in off-peak hours are possibly high. Concerning about three last variables (trip purpose is going to school, understand amercement for RLR, and know how to stop at traffic light), all of them significantly and negatively affect RLR frequency. It implies that the road users who go to school and the people who understand traffic law are less likely to violate the red light.

\section{CONCLUSION}

This study examined factors associated with RLR using questionnaire data collected in Hanoi. This paper applied the ordered probit model as a statistical method to explore influencing factors. A comprehensive discussion was conducted. The results were explained and compared with those in previous studies. We concluded that our results extend the findings that existed in the literature and provide insight into RLR behavior. It was found that males and motorcycles are associated with a higher likelihood of RLR than females and cars. Younger and lower-income road users are also possibly the red-light runners compared to the older and higher-income ones. Furthermore, the road users who are a businessman and who have a commuting trip in off-peak hours are more likely to run the red-light. On the other hand, the road users who go to school and the people who understand traffic law are less possible to commit RLR. From these results, it can be implied that increased education on traffic law is necessary to raise awareness among road users and reduce RLR. The training must focus on males, younger and lower-income drivers/motorcyclists, and motorcyclists. In addition, some countermeasures such as enforcement cameras, increment amount of the fine for violators, driving license deduction may be critical to reduce RLR.

Although our results are promising, some limitations should be noted. Firstly, our dataset has site-specific characteristics, and the results may not be generalized. To overcome this limitation, collecting data at several cities in Vietnam is necessary. Secondly, the ordered probit model that assumes homogeneity across respondents cannot investigate some hidden facts. In the future study, it must be interesting to consider heterogeneity among respondents by applying latent class - ordered probit model. In the new model, other factors (e.g., weather, waiting time, and countdown signal) pointed out by [20] need to be considered as well.

\section{ACKNOWLEDGMENT}

This research is funded by University of Transport and Communications (UTC) under grant number T2019-CT-06TD.

\section{REFERENCES}

[1]. NHTSA., 2020, Traffic safety facts 2018, National Highway Traffic Safety Administration. https://crashstats.nhtsa.dot.gov/Api/Public/ViewPublication/812981

[2]. F. Yan, B. Li, W. Zhang, G. Hu, Red-light running rates at five intersections by road user in Changsha, China: An observational study, Accident Analysis \& Prevention, 95 (2016) 381-386. https://doi.org/10.1016/j.aap.2015.06.006

[3]. A. Jensupakarn, K. Kanitpong, Influences of motorcycle rider and driver characteristics and road environment on red light running behavior at signalized intersections, Accident Analysis \& 
Prevention, 113 (2018) 317-324. https://doi.org/10.1016/j.aap.2018.02.007

[4]. R.A. Retting, R.G. Ulmer, A.F. Williams, Prevalence and characteristics of red light running crashes in the United States. Accident Analysis \& Prevention, 31 (1999) 687-694. https://doi.org/10.1016/S0001-4575(99)00029-9

[5]. R. A. Retting, A. F. Williams, D. F. Preusser, H. B. Weinstein, Classifying urban crashes for countermeasure development, Accident Analysis and Prevention, 27 (1995) 283-294. https://doi.org/10.1016/0001-4575(94)00068-W

[6]. N. Brittany, B. N. Campbell, J. D. Smith, W. G. Najm, 2004, Analysis of fatal crashes due to signal and stop sign violations, Report No. DOT HS- 809-779, National Highway Traffic Safety Administration, Washington, DC.

[7]. Insurance Institute for Highway Safety, Red light running. https://www.iihs.org/topics/red-lightrunning, (accessed 13 July 2020).

[8]. World Health Organization, 2018, Global status report on road safety 2018: Summary (No. WHO/NMH/NVI/18.20), World Health Organization.

[9]. General statistics office of Viet Nam, Socio-economic situation in the first 5 months of 2020. https://bit.ly/382A6o5, (accessed 13 July 2020).

[10]. A. M. Al-Atawi, Characteristics of red light running violations in urban areas in Tabuk, Kingdom of Saudi Arabia, IATSS research, 37 (2014) 119-123. https://doi.org/10.1016/j.iatssr.2013.08.001

[11]. X. Wang, R. Yu, C. Zhong, A field investigation of red-light-running in Shanghai, China, Transportation research part F: traffic psychology and behaviour, 37 (2016) 144-153. https://doi.org/10.1016/j.trf.2015.12.010

[12]. P. L. Chen, C. W. Pai, R. C. Jou, W. Saleh, M. S. Kuo, Exploring motorcycle red-light violation in response to pedestrian green signal countdown device, Accident Analysis \& Prevention, 75 (2015) 128-136. https://doi.org/10.1016/j.aap.2014.11.016

[13]. C.D. Yang, W.G. Najm, Examining driver behavior using data gathered from red light photo enforcement cameras, Journal of safety research, $38 \quad$ (2007) 311-321. https://doi.org/10.1016/j.jsr.2007.01.008

[14]. B.E. Porter, T.D. Berry, A nationwide survey of self-reported red light running: measuring prevalence, predictors, and perceived consequences, Accident Analysis \& Prevention, 33 (2001) 735741. https://doi.org/10.1016/S0001-4575(00)00087-7

[15]. P. Chen, G. Yu, X. Wu, Y. Ren, Y. Li, Estimation of red-light running frequency using highresolution traffic and signal data, Accident Analysis and Prevention, 102 (2017) 235-247. https://doi.org/10.1016/j.aap.2017.03.010

[16]. J.A. Bonneson, K.H. Zimmerman, Effect of yellow-interval timing on the frequency of red-light violations at urban intersections, Transportation Research Record, 1865 (2004) 20-27. https://doi.org/10.3141/1865-04

[17]. R.A. Retting, S.A. Ferguson, C.M. Farmer, Reducing red light running through longer yellow signal timing and red light camera enforcement: results of a field investigation, Accident Analysis \& Prevention, 40 (2008) 327-333. https://doi.org/10.1016/j.aap.2007.06.011

[18]. K. Long, L.D. Han, Q. Yang, Effects of countdown timers on driver behavior after the yellow onset at Chinese intersections, Traffic injury prevention, 12 (2011) 538-544. https://doi.org/10.1080/15389588.2011.593010

[19]. X. C. Vuong, R.-F. Mou, H. S. Nguyen, T. T. Vu, Red Light Running of Motorcycles at Signalized Intersections in Vietnam: Influential Factors and Countermeasures, Proceeding of the 2018 International Conference on Building Smart Cities in Vietnam: Vision and Solutions, 2018.

[20]. T. D. Chu, T. A. Bui, A study on red-light running in Hanoi based on questionnaire survey, Proceeding of ICSCE 2020 - The 3rd International Conference on Sustainability in Civil Engineering, 2020. 
Transport and Communications Science Journal, Vol. 72, Issue 7 (09/2021), 800-810

[21]. V. H. Mai, T. D. Chu, Q. H. Vu, Investigating Signal Violations in Mixed Traffic in Hanoi City, Proceedings of the Eastern Asia Society for Transportation Studies, 2019.

[22]. Q. V. Tran, A. T. Vu, Analysis of traffic accidents at signalized intersections, Proceeding of 7th ATRANS symposium: young researcher's forum 2014 "Transportation for a Better Life: Towards Better ASEAN Connectivity and Safety", 2014.

[23]. W. H. Greene, D. A. Hensher, Modeling ordered choices: A primer, Cambridge University Press, 2010.

[24]. O. Torres-Reyna, Getting started in Logit and ordered logit regression, Princeton University, 2010. https://www.princeton.edu/ otorres/Logit.pdf

[25]. D. McFadden, Quantitative Methods for Analyzing Travel Behaviour of Individuals: Some Recent Developments, No 474, Cowles Foundation Discussion Papers, Cowles Foundation for Research in Economics, Yale University, 1977. https://ideas.repec.org/p/cwl/cwldpp/474.html 